Beobachtung des Planeten (134) auf der Sternwarte in Lund.

$\begin{array}{ccccc}1873 & \text { M. Zt. Lund } & \text { AR. (134) } & \text { Decl. (134) } & \text { Beob. } \\ \text { October 2 } & \text { 9h 56m 9s } & \text { 0h 3m9s.92 } & +7048^{\prime} 9^{\prime \prime} .5 & \text { Möller }\end{array}$

Mittlerer Ort des Vergleichsterns 1873.0.
A.R. $=0$ h $3 \mathrm{~m} \mathrm{27s.09}$
Decl. $=+7^{\circ} 52^{\prime} 17^{\prime \prime} .3$
Berl. Merid.-Beob.

Lund 1873, October 3.

Axel Möller.

\title{
Schreiben des Herrn W. Tempel an den Herausgeber.
}

Ich erlaube mir, Ihnen hiermit die Fortsetzung meiner Cometenbeobachtungen zu übersenden. Die einzelnen Zahlen der Vergleichungen bedeuten, dass die Hälfte obere und die Hälfte untere Durchgänge sind. Zwei nebeneinander stehende Zahlen zeigen die verschiedenen Durchgänge an. - Die Position des Vergleichsterns $1123+57^{\circ}$, welche ich am 13. September durch 4 Vergleichungen mit $1133+570$ erhielt, ist vielleicht nicht ganz genau. Den mittleren Ort für 1873.0 von 1133 nahm ich an: $\mathrm{AR}=122^{\circ} 55^{\prime} 58^{\prime \prime} .68$ $\delta=+57054^{\prime} 11^{\prime \prime} .3$.

Den Cometen 1873 II. versuchte ich vergeblich im September mehrere Male zu messen; er war aber für den Plössl zu schwach. Mit meinem Fernrohre fand ich ibn an 2. October, ohne Ephemeride, noch ziemlich gross, wenn auch sehr schwach und verwachsen.

Von dem schönen Henry'schen Cometen machte ich mir am 30. August und 3. September Skizzen von seinem interessanten Schweife. Am 28. August zeigte der Comet in meinem Fernrohre sicher noch keinen Schweif, wenn auch beim Durchgange in Kreismikrometer dentlich ein früheres Heraustreten ans dem Ringe eine Schweifspur anzeigte. Am 29. August war ein kleiner schmaler Schweif von 1 Grad Länge sichtbar. Der Kopf war eine runde ziemlich scharf begrenzte, nach der Mitte stark verdichtete Nebelmasse von wenigstens $8^{\prime}$ bis $10^{\prime}$ Durchmesser. Mit starker Vergrösserung erschien er wie ein aufgelösster Nebelflecken, doch ohne Spur eines helleren Kernes. Der Schweif fing nicht unmittelbar vom Kopfe an, sondern es war ein Zwischenraum von mehreren Minuten und dann begann er mit einer feinen Spitze von vielleicht kaum einer Minute Breite, erweiterte sich und endigte breit und verwaschen. Am 3. September war dieser Schweif von mehr als 3 Graden Länge, die Spitze fing $2^{\prime}$ bis $3^{\prime}$ von der äusseren Cometenhülle an, war in der Entfernung von $15^{\prime}$ kaum $2^{\prime}$ breit aber hell und scharf, wurde nach und nach breiter und endigte verwaschen mit wenigstens $16^{\prime}$ bis $20^{\prime}$ Breite. - Deutlich sah ich das Aufflackern in diesem Schweife; in dem schmaleren Theile war es, als gingen Lichtwogen auf und $a b$; und das breite diffuse Ende des Schweifes schien aus lauter parallelen lichten Linien ebenfalls wogenartig heller und schwächer werdend, «u bestehen.

Meine Skizze giebt wohl deutlich wieder, wie der Comet und sein sonderbarer Schweif sich in meinem hellen und grossen Sehfelde mit 24 maliger Vergrösserung projectirte; aber das scheinbar Lebendige im Schweife ist nicht möglich zu zeichnen. - Am 5. September bei Vollmondschein war im Plössl während der Beobachtung keine Spur eines Schweifes sichtbar. Nach Untergang des Mondes bei schon heraufkommender Dämmerung sah ich den Cometen mit 40 maliger Vergrösserung mit meinem Fernrohre, und es schien, als ginge der Schweif nun sogleich mit der Breite des Kopfes, von ihm ausgehend fort. Doch war die Dämmerung zu hell und in den folgenden Tagen erlaubten leider Wolken und sein niedriger Stand bier nicht den Cometen weiter zu beobachten.

Comet II. 1873, entdeckt am 3. Juli.

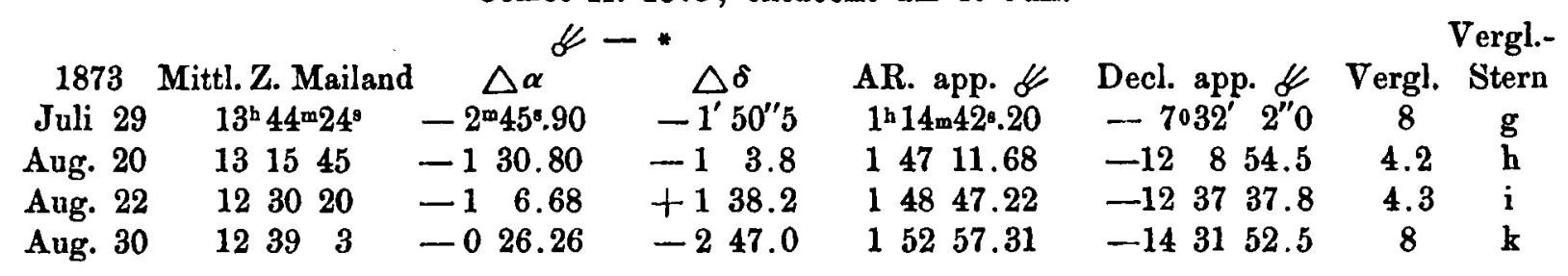

